\title{
Mating system variation in hybridizing irises: Effects of phenology and floral densities on family outcrossing rates
}

\author{
M. B. CRUZAN 1 , J. L. HAMRICK ${ }^{1,2}$, M. L. ARNOLD ${ }^{1 *}$ \& B. D. BENNETT ${ }^{3}$ \\ Departments of ' Genetics and ${ }^{2}$ Botany, University of Georgia, Athens, GA 30602 and ${ }^{3}$ Department of Biological \\ Sciences, PO Box 559, Arkansas State University, AR 72467-0599, U.S.A.
}

\begin{abstract}
The frequency of outcrossing in two hybridizing species of Iris was estimated for populations and for individual fruits. Effects of floral phenology and the local densities of flowers on outcrossing rates were examined and the potential for hybrid seed formation under different pollen environments was assessed. The populations examined differed with respect to the spatial distribution of plants and the level of genetic structure; the I. fulva population consisted of a number of low density patches and appeared to have some genetic differentiation whereas the I. hexagona population consisted of a single high-density experimental plot of randomly distributed genotypes. Population outcrossing rate estimates were relatively high $(0.67-0.90)$ for both species. The distribution of family outcrossing rates tended to be bimodal for both species with individual fruits either having the majority of seeds fertilized by outcrossed donors or being almost entirely selfed. The frequency of outcrossed fruits increased with the number of flowers open at other plants and decreased when more flowers were open on the same stem in I. hexagona. In I. fulva the opposite trends were apparent; outcrossing decreased when more flowers were open on other stems and increased when more flowers were open on the same stem. The unexpected responses of outcrossing frequency in $I$. fulva may have been a consequence of higher levels of vegetative reproduction and genetic structure and the behaviour of pollen vectors. Differences in pollen prepotency and the higher selfing rates observed at low floral densities in I. hexagona may have contributed to the observed patterns of hybrid seed formation. The analyses of family outcrossing rates provide important information on factors responsible for mating system variation and evolution.
\end{abstract}

Keywords: floral density, hybridization, Iris, mating system variation, phenology.

\section{Introduction}

Studies of plant mating systems have revealed considerable variation among species and populations in the proportion of selfed and outcrossed progeny produced (Schemske \& Lande, 1985; Barrett \& Eckert, 1990). Although theoretical analyses have predicted the existence of completely selfing or outcrossing populations (Lande \& Schemske, 1985), many plants appear to produce mixtures of selfed and outcrossed progeny (Harding, 1970; Harding et al., 1974; Barrett \& Husband, 1990). These mixed mating systems are of particular interest because of the information they may provide about factors responsible for the

*Correspondence. maintenance and evolution of floral syndromes that promote different levels of selfing and outcrossing. It has been suggested that mixed mating systems are sensitive to the composition of pollen loads (Holsinger, 1991) and that variation in the pollen environment combined with differences in pollen prepotency can result in facultatively outcrossing species (M. B. Cruzan \& S. C. H. Barrett, unpublished data). Although environmental influences on the mating systems of plants are generally considered to be important, there are few available data that examine the effects of flower density and phenology on the frequency of selfing and outcrossing within populations (Barrett \& Eckert, 1990).

For closely related species that are growing sympatrically, variation in the pollen environment may have consequences for the frequency of hybrid seed 
formation. Studies of sympatric Louisiana irises indicate that interspecific matings are rare but tend to occur when flowers of one species are numerically dominant (Arnold et al., 1993). If the mating systems of these species were sensitive to variation in the pollen environment, then the opportunity for interspecific fertilizations may vary with flowering densities. Analysis of the response of outcrossing rates for individual flowers to variation in the pollen environment may provide an indication of how the frequency of hybrid seed formation varies over the flowering season.

We examined mating system variation in a natural population of Iris fulva Ker-Gawler and an experimentally introduced population of Iris hexagona Walter. Hybridization between these two species is well documented and has been the subject of considerable attention over the last half-century (Riley, 1938; Anderson, 1949; Randolph et al., 1967; Arnold et al., 1990a, b, 1991, 1992). Plants of Iris fulva and $I$. hexagona are associated with swamps, streams and bayous in the south eastern U.S.A. and overlap in their distributions in the Mississippi River delta region of Louisiana. Leaves of these plants arise from spreading rhizomes in December and January and flowering stems are produced in March and April. Plants of these species have largely coincidental flowering times that continue approximately 3-4 weeks (Arnold et al., 1993). The differing morphologies of the flowers of these species can be classified into two distinct 'pollination syndromes' (Faegri \& van der Pijl, 1966); the smaller brick red flowers of $I$. fulva are indicative of hummingbird pollination and the larger dark blue flowers of $I$. hexagona suggest an association with large-bodied bees. Both hummingbirds and bumble bees are common visitors to flowers in the study area. Although these pollinators often forage on their associated flower types, interspecific visits do occur (Arnold et al., 1993; M. B. Cruzan \& M. L. Arnold, unpublished data).

In an effort to assess the strength of reproductive barriers between Iris species Arnold et al. (1993) introduced 200 rhizomes of $I$. hexagona into an I. fulva population that was distributed along the length of a natural bayou. Results of this experiment indicate that although plants of the two species were in close proximity and overlapped in flowering time, hybrid seed was formed at a rate of less than 1 per cent of total seed production. We used six polymorphic allozyme loci to evaluate how the mating systems of $I$. fulva and I. hexagona varied in response to the flowering stage of the population, the spatial distribution of flowering individuals and the local abundance of pollen bearing flowers.

\section{Materials and methods}

The date of opening for all flowers on I. fulva plants and the experimentally introduced $I$. hexagona plants was recorded during March and April of 1990. Seeds from plants producing at least two fruits were sampled by taking all of the seeds contained in one of the three locules in each of the first two fruits produced. The spatial position of each I. fulva flowering stalk in the population was mapped. Within the experimental plot individual shoots were at a relatively high density and the position of each $I$. hexagona individual was not recorded. Plants of I. fulva tend to occur as isolated individuals or in low density patches of separate shoots. For the purposes of analysis, 30 spatially isolated patches were identified that contained between 1 and 43 individuals. All $I$. hexagona plants occurred in one patch (the experimental plot). Flowering stalks were not separated by more than $10 \mathrm{~m}$ within any patch.

\section{Analysis of flowering phenology and frequency}

The timing of the availability of pollen and receptivity of stigmas was used to determine the number of potential outcross and self pollen donors for each flower. Pollen is available from the flowers of these species beginning the first day of blooming. The receptive surface of the stigma, however, is concealed until the second day in I. hexagona and the third day in I. fulva when the stigma lobes separate from the underside of the flattened style (S. Carney et al., unpublished data). Flowers begin wilting at the end of the third day and by the fourth day the sepals have curled over the style concealing the stigma once again. This difference in the timing of the functional gender of flowers should have implications for mating patterns; the number of potential donors will include all flowers bearing pollen on the day a flower is receptive.

The sizes of the self and outcross flower pools were calculated according to the observations of the gender phase of other flowers occurring in the patch. For both species the outcross flower pool was calculated as the cumulative total of flowers opening on other plants within the same patch over the 3-day period following the first day each flower opened. The number of flowers potentially donating self pollen was calculated in the same way but only flowers opening on the same stem as the receptive flower were included.

\section{Electrophoretic analysis}

Between 6 and 12 seeds from each fruit were assayed for six electrophoretic loci using previously described 
methods (Arnold et al., 1990b). The loci examined (fluorescent esterase, $F E-1$; glutamate oxaloacetate transaminase, GOT-3; isocitrate dehydrogenase, $I D H$ 2 ; 6-phosphate dehydrogenase, $6 P-2$ and $6 P$-3; phospho-glucoisomerase, $P G I-2$ ) were polymorphic in both species. Maternal genotypes were determined for 35 of 47 plants in I. hexagona and 19 of 39 plants in I. fulva from leaf material that had been snap-frozen in liquid nitrogen and stored at $-70^{\circ} \mathrm{C}$.

\section{Population outcrossing rates}

The unknown maternal genotypes were inferred using the method described by Brown \& Allard (1970). Population estimates of single locus and multilocus outcrossing rates $(t)$ for each species were obtained using the maximum likelihood procedures of Ritland \& Jain (1981). Standard errors of $t$ and the allele frequencies in the pollen and ovule pools at each locus were estimated by bootstrapping the data 100 times.

\section{Family outcrossing rates}

Multilocus estimates of the outcrossing rate for individual fruits were calculated in two ways. Maximum likelihood estimates were made with the Ritland \& Jain (1981) methods used for population estimates and standard errors were obtained by making ten bootstraps for each fruit. Apparent outcrossing rate estimates were obtained for individual fruits using a modification of the methods of Shaw et al.(1981). The frequency of apparently outcrossed progeny in each family can be determined by comparing the multilocus genotype of each seed to the maternal genotype (Shaw et al., 1981). According to this method, the presence of an allele in a progeny genotype that is not present in the seed parent indicates a detectable outcross event. The detectable outcrossing rate for a single family $\left(t_{\mathrm{dj}}\right)$ is then the number of detected outcrossing events divided by the total number of progeny produced $\left(n_{\mathrm{j}}\right)$ $N_{\mathrm{j}}$ ).

In addition to the detectable outcross events there will be some fraction of undetected outcrossed progeny. Progeny not possessing alleles that are unique with respect to the maternal parent could have been produced by either selfing or by outcrossing to an individual having a similar genotype. The probability of a plant producing an undetectable outcross event, $P(u)_{\text {, }}$, will be proportional to the frequency of its alleles in the outcross pollen pool (Shaw et al., 1981; Morgan \& Barrett, 1990). For a multilocus genotype the probability of producing an undetected outcross event is the product across loci of the frequency of maternal alleles in the pollen pool:
$P(u)_{\mathrm{j}}=\prod_{\mathrm{k}=1}^{m} \sum_{\mathrm{i}} p_{\mathrm{ik}}$

where $p_{\mathrm{ik}}$ is the frequency of the alleles at each locus present in the maternal genotype. The expected proportion of undetected outcross events will be large for maternal genotypes possessing alleles that have a high frequency in the pollen pool and small for relatively rare genotypes. The fraction of undetected outcross progeny for a maternal genotype can then be obtained from its probability of producing an undetected outcross progeny among the ambiguous progeny $\left(N_{\mathrm{j}}-n_{\mathrm{j}}\right)$ and its outcrossing rate:

$t_{\mathrm{uj}}=\frac{\hat{t}_{\mathrm{j}} P(u)_{\mathrm{j}}\left(N_{\mathrm{j}}-n_{\mathrm{j}}\right)}{N_{\mathrm{j}}}$

The estimate of the outcrossing rate for each maternal family is thus affected by the frequency of alleles in the outcross pollen pool. For a population of maternal plants, the composition of the effective outcross pollen pool can be estimated from the genotypes of the detected outcrossed progeny and the expected frequency of undetected outcross events in each family. Taking into account that the family outcrossing rates are sensitive to the composition of the outcross pollen pool results in the recursive equations:

$p_{\mathrm{ik}}^{\prime}=\frac{x_{\mathrm{i}}}{x_{\mathrm{k}}}+\sum_{\mathrm{j}} t_{\mathrm{j} j}^{\prime} p_{\mathrm{ik}} \quad$ and

$t_{\mathrm{aj}}^{\prime}=t_{\mathrm{dj}}+\frac{\left(\prod \sum p_{\mathrm{ik}}^{\prime}\right) t_{\mathrm{aj}}\left(N_{\mathrm{j}}-n_{\mathrm{j}}\right)}{N_{\mathrm{j}}}$,

where $x_{\mathrm{i}}$ is the number of alleles of type $\mathrm{i}$ found in the detected outcross progeny in all families and $x_{\mathrm{k}}$ is the total number of outcross pollen alleles found at the locus. By iterating these equations and substituting the values for $p_{\mathrm{ik}}^{\prime}$ and $t_{\mathrm{aj}}^{\prime}$ until there was a very small difference $(P<0.001)$ between successive iterations we obtained estimates of the frequency of alleles in the outcross pollen pool and the outcrossing rate for each family. Estimates of the variance in apparent outcrossing rates were made assuming a binomial error distribution(Shaw et al., 1981).

\section{Data analysis}

The effect of the day of the flowering season and the number of self and outcross flowers present in each patch on the number of seeds produced and the estimates of family outcrossing rates were examined. Effects of phenology and flowering densities on differences in seed set among flowers in each species were 
assessed using multiple regression analyses using the REG procedure of SAS (SAS Institue, 1985). Individual fruit outcrossing rates in each species were analysed using both the maximum likelihood $\left(t_{\mathrm{ml}}\right)$ and apparent $\left(t_{\mathrm{a}}\right)$ estimates. For both estimates, fruits were classified as selfed if the 95 per cent confidence interval of the family outcrossing rate overlapped zero or outcrossed if the confidence interval did not overlap zero. These mating classifications were then used as dependent variables in logistic regression analyses with flowering day and the numbers of self and outcross flowers available in the same patch as independent variables using the CATMOD procedure of SAS (SAS Institute, 1985).

\section{Results}

\section{Outcrossing rate estimates}

Population outcrossing rate estimates were relatively high for both species (Table 1). The mean single and multiple locus estimates were similar in Iris hexagona but the single locus estimate was somewhat smaller than the multilocus estimate in I. fulva indicating the presence of genetic differentiation in this population (Brown, 1990). Individual loci displayed various degrees of fit to the mixed mating model as indicated by the size of chi-square values (Table 1 ). In I. hexagona only GOT-3 showed a relatively large deviation whereas in I. fulva, PGI-2, GOT-3, and FE-I all had large chi-square values. Allele frequencies differed between pollen and ovule pools for several loci, including FE-1 in I. fulva and GOT-3 and 6P-2 in I. hexagona (Table 1).

The family maximum likelihood outcrossing rate estimates did not converge for 19 of the I. fulva families and 14 of the $I$. hexagona families. The estimates that did converge ranged from zero to values greater than one (estimates were constrained to values less than 2.0; Ritland \& Jain, 1981) in both species and their means were lower than the single locus and multilocus population estimates (Table 2).

Apparent outcrossing rates converged for all families to yield estimates that ranged from zero to one in both species (Fig. 1). Values of $t_{\mathrm{a}}$ were stongly corre-

Table 1 Pollen $(P)$ and ovule $(O)$ allele frequencies and outcrossing rate estimates for Iris fulva and I. hexagona. Chi-square tests are for the fit of each locus to the expected allele frequencies under the mixed mating model. One locus was excluded $(F E-1)$ for outcrossing rate estimates in 1. fulva

\begin{tabular}{|c|c|c|c|c|c|c|c|c|}
\hline \multirow[b]{3}{*}{ Locus } & \multirow[b]{3}{*}{ Scored } & \multicolumn{6}{|c|}{ Allele frequencies } & \multirow[b]{3}{*}{$\chi^{2}$} \\
\hline & & \multicolumn{3}{|l|}{ Pollen } & \multicolumn{3}{|c|}{ Ovules } & \\
\hline & & $P_{1}$ & $P_{2}$ & $P_{3}$ & $O_{1}$ & $\mathrm{O}_{2}$ & $\mathrm{O}_{3}$ & \\
\hline \multicolumn{9}{|c|}{ Iris fulva } \\
\hline$P G I-2$ & 334 & 0.909 & 0.087 & 0.004 & 0.885 & 0.115 & 0.000 & 20.51 \\
\hline GOT-3 & 237 & 0.285 & 0.432 & 0.283 & 0.485 & 0.015 & 0.500 & 47.85 \\
\hline $6 P-2$ & 315 & 0.679 & 0.308 & 0.013 & 0.700 & 0.300 & 0.000 & 16.23 \\
\hline $6 P-3$ & 354 & 0.985 & 0.015 & - & 1.000 & 0.000 & - & 0.00 \\
\hline$F E-1^{* * *}$ & 356 & 0.972 & 0.028 & - & 0.738 & 0.262 & - & 115.59 \\
\hline$I D H-2$ & 269 & 0.954 & 0.046 & - & 0.992 & 0.008 & - & 0.33 \\
\hline
\end{tabular}

Mean single-locus outcrossing rate $=0.667 \pm 0.000$

Multi-locus outcrossing rate $=0.752 \pm 0.000$

Iris hexagona

$\begin{array}{llllllllr}P G I-2 & 323 & 0.411 & 0.582 & 0.007 & 0.456 & 0.544 & 0.000 & 10.73 \\ G O T-3^{* * * *} & 322 & 0.659 & 0.341 & - & 0.921 & 0.079 & - & 21.01 \\ 6 P-2 * * & 316 & 0.856 & 0.144 & - & 0.974 & 0.026 & - & 2.17 \\ 6 P-3 & 322 & 0.514 & 0.475 & 0.010 & 0.518 & 0.482 & 0.000 & 0.33 \\ F E-1 & 324 & 0.918 & 0.082 & - & 0.965 & 0.035 & - & 1.45 \\ I D H-2 & 325 & 0.979 & 0.021 & - & 1.000 & 0.000 & - & 2.94\end{array}$

Mean single-locus outcrossing rate $=0.879 \pm 0.016$

Multi-locus outcrossing rate $=0.900 \pm 0.018$

***ollen and ovule allele frequencies differ at $P<0.01$; *** $P<0.001$. 
lated with $t_{\mathrm{ml}}$ family estimates in I. hexagona $(r=0.82$, $P=0.0001, N=43$ ) but the relationship was much weaker for $I$. fulva families $(r=0.27, P=0.0739$, $N=46$ ). The mean of family estimates of $t_{\mathrm{a}}$ was similar to the value obtained from the $t_{\mathrm{ml}}$ procedure for $I$. hexagona but was lower than the mean family $t_{\mathrm{ml}}$ estimates for I. fulva (Table 2).

The majority of the variation in apparent outcrossing rates was due to variation in detectable outcross events in both I. fulva $(r=0.99, P<0.0001)$ and in $I$. hexagona $(r=0.82, P<0.0001)$. The average probability of producing an undetected outcross seed by maternal parents $P(u)$ was relatively large in $I$. hexagona but tended to be much smaller in $I$. fulva (Table 2). The magnitude of $P(u)$ influenced the relative contribution of detectable outcross events to $t_{\mathrm{a}}$ estimates that were greater than zero; in $I$. fulva, $t_{\mathrm{d}}$ constituted 94.0 per cent $(N=39$, standard error $=0.78)$ of the apparent outcrossing rates whereas in $I$. hexagona 64.3 per cent $(N=47$, standard error $=4.39)$ of $t_{\mathrm{a}}$ was accounted for by detectable outcrosses.

\section{Effects of phenology and flowering density}

Seed production for individual fruits was affected by the number of outcross flowers available in the same patch in I. fulva and by the time of flowering in both species (Table 3). For I. fulva, seed production increased when more flowers were open on other stems in the same patch and seed numbers per fruit tended to decrease later in the flowering season. In $I$. hexagona seed production was also lower for flowers opening later in the season but there was not a strong effect of the number of outcross flowers available (Table 3). The number of flowers open on the same stem did not have a strong effect on seed production in either species (Table 3).

The day of flowering, number of flowers open on the same stem and the number of flowers open on other stems in the same patch all influenced the frequency of outcrossed fruits in I. fulva whereas only the number of self and outcross flowers open in the experimental plot had effects on the frequency of outcrossed fruits in $I$. hexagona (Table 4). Qualitative results for both species were similar for classifications based on $t_{\mathrm{m}}$ and $t_{\mathrm{a}}$ but the strength of individual effects differed for the two estimates (Table 4). The different results for the two mating system estimates may have been due to a weak correspondence between them; classifications based on $t_{\mathrm{ml}}$ and $t_{\mathrm{a}}$ methods differed for 31 of the $I$. fulva fruits and 35 of the $I$. hexagona fruits.

The frequency of outcrossing based on both the $t_{\mathrm{ml}}$ and $t_{\mathrm{a}}$ estimates decreased with the number of self flowers and increased with increasing numbers of flowers on other stems in I. hexagona (Table 4). In I. fulva the opposite trend was apparent: the frequency of outcrossed fruits increased when more flowers were open on the same stem and decreased when more flowers were open on other stems in the same patch. The pattern found for flowering day differed somewhat for the two estimates. In $I$. fulva outcrossing frequencies decreased for flowers that opened later in the season but this effect was more apparent for the classifications made from $t_{\mathrm{a}}$ (Table 4). In I. hexagona flowering day did not have a strong effect on the frequency of outcrossing based on either estimate (Table 4).

\section{Discussion}

Variation in the frequency of selfing and outcrossing among individual flowers occurred as a result of the

Table 2 Outcrossing rates, number of seeds produced per fruit and the number of self and outcross flowers available to each flower in Iris fulva and I. hexagona. Population estimates are from a multilocus maximum likelihood procedure $\left(t_{\mathrm{ml}}\right)$. The mean of family outcrossing rates for individual fruits are given for the $t_{\mathrm{ml}}$ procedure and for the apparent $\left(t_{\mathrm{a}}\right)$ and detectable $\left(t_{\mathrm{d}}\right)$ outcrossing rate estimates and the probability of producing undetected outcross progeny $(P(u))$

\begin{tabular}{|c|c|c|c|c|c|c|}
\hline \multirow[b]{2}{*}{ Variable } & \multicolumn{3}{|c|}{ I. fulva } & \multicolumn{3}{|c|}{ 1. hexagona } \\
\hline & $N$ & Value & Error & $N$ & Value & Error \\
\hline$t_{\mathrm{ml}}$ & 46 & 0.53 & 0.080 & 43 & 0.72 & 0.090 \\
\hline$t_{\mathrm{a}}$ & 65 & 0.33 & 0.043 & 57 & 0.70 & 0.047 \\
\hline Detected $\left(t_{\mathrm{d}}\right)$ & 65 & 0.31 & 0.041 & 57 & 0.47 & 0.048 \\
\hline Undetected $(P(u))$ & 65 & 0.13 & 0.018 & 57 & 0.81 & 0.036 \\
\hline Seed production $(1 / 3)$ & 65 & 11.89 & 0.642 & 57 & 13.63 & 0.846 \\
\hline Outcross flowers & 65 & 31.92 & 2.680 & 57 & 47.46 & 2.235 \\
\hline Self flowers & 65 & 2.00 & 0.103 & 57 & 1.68 & 0.097 \\
\hline
\end{tabular}




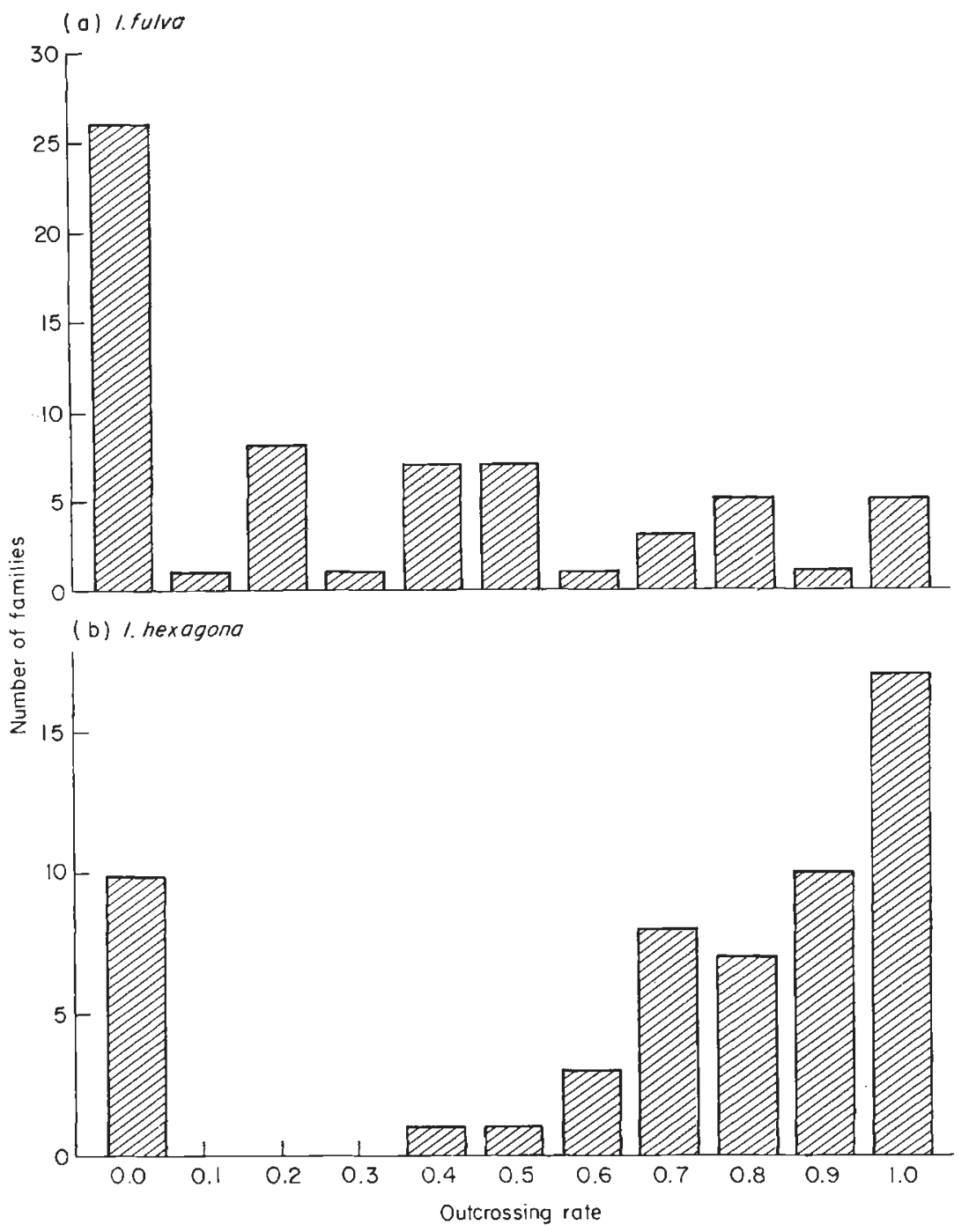

Table 3 Effect of day of flowering (day), number of flowers in male phase on the same plant (self flowers) and the number of flowers in male phase present on neighbouring plants (outcross flowers) on seed set in Iris fulva and I. hexagona. Ftests are made using type II sums of squares from the REG procedure of SAS

\begin{tabular}{|c|c|c|c|c|c|c|c|c|}
\hline \multirow[b]{2}{*}{ Source } & \multicolumn{4}{|c|}{ I. fulva } & \multicolumn{4}{|c|}{ 1. hexagona } \\
\hline & d.f. & Slope & SS & $F$ & d.f. & Slope & SS & $F$ \\
\hline Day & 1 & -0.664 & 201.2 & $9.63^{* *}$ & 1 & -0.965 & 191.8 & $5.06^{*}$ \\
\hline Self flowers & 1 & 0.666 & 13.9 & 1.50 & 1 & 1.023 & 30.9 & 0.82 \\
\hline Outcross flowers & 1 & 0.103 & 258.1 & $12.36^{* * *}$ & 1 & 0.096 & 53.8 & 1.42 \\
\hline Error & 55 & - & 1148.8 & - & 53 & - & 2006.9 & - \\
\hline
\end{tabular}

*** $P<0.001,{ }^{* *} P<0.01,{ }^{*} P<0.05$.
Fig. 1 Distribution of family outcrossing rates $\left(t_{\mathrm{a}}\right)$ in Iris fulva and $I$. hexagona. 
Table 4 Effect of day of flowering (day), number of flowers in male phase on the same plant (self) and the number of flowers in male phase present on neighbouring plants (outcross) on maximum likelihood $\left(t_{\mathrm{ml}}\right)$ and apparent $\left(t_{\mathrm{a}}\right)$ outcrossing rate estimates in Iris fulva and I. hexagona. Parameters and chi-square tests are from logistic regression models with families classified as selfed or outcrossed. The likelihood ratio ( $\mathrm{L}$ ratio) indicates the degree of fit of the model

\begin{tabular}{|c|c|c|c|c|c|c|c|c|c|c|}
\hline \multirow[b]{2}{*}{ Source } & \multicolumn{5}{|c|}{ I. fulva } & \multicolumn{5}{|c|}{ I. hexagona } \\
\hline & d.f. & $t_{\mathrm{ml}}$ & $\chi^{2}$ & $t_{\mathrm{a}}$ & $\chi^{2}$ & d.f. & $t_{\mathrm{ml}}$ & $\chi^{2}$ & $t_{\mathrm{a}}$ & $\chi^{2}$ \\
\hline Day & 1 & -0.085 & 2.23 & -0.207 & $20.42^{* * *}$ & 1 & 0.085 & 1.49 & -0.069 & 0.64 \\
\hline Self & 1 & 0.370 & $3.26 \dagger$ & 0.368 & $5.26^{*}$ & 1 & -0.267 & 1.25 & -0.522 & $6.13^{* *}$ \\
\hline Outcross & 1 & -0.020 & $7.68^{* * * *}$ & -0.013 & $5.36^{*}$ & 1 & 0.008 & 0.37 & 0.050 & $9.53^{* * *}$ \\
\hline L ratio & 41 & - & $235.48^{* * *}$ & - & $364.41^{* * * *}$ & 24 & - & $142.74^{* * * *}$ & - & $148.28^{* * *}$ \\
\hline
\end{tabular}

*** $P<0.001,{ }^{* *} P<0.01,{ }^{*} P<0.05, \dagger P<0.10$.

time of flowering and the density of flowers bearing self and outcross pollen. The two populations exhibited different patterns of dispersion and levels of genetic structure that may have had implications for the response of the mating system parameters to flowering density. In the I. hexagona sample, which consisted of a dense patch of randomly distributed genotypes, the frequency of outcrossing increased with the frequency of pollen bearing flowers on other plants and decreased when more flowers were open on the same stem as the recipient flower. The opposite pattern found in I. fulva may be a consequence of the highly dispersed distribution of individuals in the population, asexual reproduction that has produced patches of genetically identical individuals and patterns of local mating to similar genotypes.

The response of outcrossing rate estimates to different levels of genetic structure and clonality will depend on the underlying assumptions of the models on which estimates are based and the way in which multilocus data is used. For both estimation procedures the $I$. hexagona population may have more closely approached model assumptions. Departures from random outcrossing and higher levels of genetic differentiation in the I. fulva population may have had different effects on the two mating system estimates.

\section{Outcrossing rate estimation}

Methods for the estimation of mating system parameters have been derived with the purpose of achieving two separate goals: (1) using effective selfing rates to assess the level of inbreeding occurring in a population (Ritland, 1984, 1986; Brown, 1990), and (2) using estimates of actual selfing rates to examine the demographic, ecological and genetic factors that influence the frequency of self-fertilization (Harding \& Tucker,
1964; Humphreys \& Gale, 1974; Ennos \& Clegg, 1982; Schoen, 1982; Ellstrand \& Foster, 1983; Smyth \& Hamrick, 1987; Ritland \& Ganders, 1985; Barrett \& Husband, 1990; Motten \& Antonovics, 1992). Effective selfing parameters include biparental inbreeding whereas the actual selfing rate includes only those matings that resulted from fertilizations by pollen from the same individual. Although it would be valuable to determine actual selfing with genetic markers, in reality the calculation of this parameter would not be possible unless every individual in the population possessed a unique genotype. Consequently, all estimates of $t$ include some amount of biparental inbreeding (Brown, 1990).

The estimate of apparent outcrossing rate used in the current study is based primarily on the frequency of detectable outcross genotypes and makes separate estimates for each individual progeny array. Measures of outcrossing based on the number of detected outcrosses provide a reliable indication of the minimum number of outcrossed progeny (Shaw et al., 1981; Brown et al., 1985). It has been recognized, however, that maternal genotypes differ in their probability of producing undectable outcrossed progeny (Shaw et al., 1981; Morgan \& Barrett, 1990). We have used a measure of the allele frequencies in the outcross pollen pool to provide an estimate of the family outcrossing rate that includes both the detected and the undetected outcrossed matings. The outcross pollen pool was derived from the parental contribution to progeny genotypes, alleviating the possibility of biases introduced through the use of maternal genotypes to predict pollen allele frequencies (Schoen \& Clegg, 1984). The method used here assumes that individual allele frequencies in the outcross pollen pool are temporally and spatially constant but does not make restrictive assumptions about the frequency of pollen genotypes 
in the outcrossed progeny (e.g. random outcrossing: Ritland \& Jain, 1981; or one pollen parent: Schoen \& Clegg, 1984).

The lower mean estimate of apparent outcrossing in I. fulva compared with the maximum likelihood estimate could result from either a greater sensitivity of apparent outcrossing rates to population structure or the different ranges of values allowed by the two procedures. Values of $t_{\mathrm{ml}}$ greater than one may inflate the average value obtained. When these are rescaled to a maximum of one, however, the mean value of 0.46 is still larger than the mean for $t_{\mathrm{a}}$ in $I$. fulva and in $I$. hexagona the mean $t_{\mathrm{ml}}$ is reduced to 0.58 , which is lower than the mean $t_{\mathrm{a}}$ for this species.

Estimated outcrossing rates will be lower than the actual outcrossing experienced by plants if a larger than random proportion of the outcross matings are to similar genotypes. The $t_{\mathrm{ml}}$ procedure may avoid some of this bias by combining information from all loci in a joint estimation procedure (Brown et al., 1985). Comparison of the two Iris populations examined provides evidence that the multilocus maximum likelihood method produces a closer approximation of the actual selfing rate. The mean estimate of $t_{\mathrm{a}}$ was somewhat lower than the mean family $t_{\mathrm{ml}}$ in the I. fulva population which was relatively undisturbed and, according to the lower single locus population $t_{\mathrm{ml}}$ estimate, possessed some level of genetic differentiation. In the I. hexagona population, which consisted of randomly distributed genotypes, the mean $t_{\mathrm{ml}}$ and $t_{\mathrm{a}}$ family outcrossing estimates were very similar.

By making full use of the genotypic information available, maximum likelihood procedures (Ritland \& Jain, 1981; Schoen \& Clegg, 1984) may provide better estimates of population parameters; however, restrictions on genotypic frequencies can create difficulties for family level estimates of outcrossing rates. In the current study and other analyses of individual progeny arrays (Morgan \& Barrett, 1990) a large fraction of the family $t_{\mathrm{ml}}$ estimates failed to converge, apparently because of a lack of fit to the assumptions of the mixed mating model. Small progeny samples may contribute to lack of convergence but even with larger arrays, a correlation among outcross progeny genotypes can lead to failure of the Ritland \& Jain (1981) methodology (Morgan \& Barrett, 1990). The reliable functioning of the apparent outcrossing model under a variety of mating patterns makes it more desirable for obtaining estimates from individual progeny arrays.

A drawback to estimating mating system parameters using the apparent outcross methodology is its reduced sensitivity to low outcrossing rates (Brown et al., 1985), particularly when few progeny are sampled and the probabilities of undetected outcrosses are high (Fig. 2).
This bias may have been partly responsible for the bimodality of $t_{\mathrm{a}}$ estimates in $I$. hexagona. The experimental plot contained relatively few genotypes, most of which were represented by a large number of individuals. As a result the probabilities of undetected outcrosses for plants in this population tended to be high and none of the non-zero estimates obtained was less than 0.4 (Fig. 1). With relatively small progeny arrays low outcrossing rates are difficult to detect, so some fraction of the families that appeared to be completely selfed in I. hexagona may actually have contained low frequencies of outcrossed progeny. The family outcrossing rate estimates would also tend to be biased downward slightly for high outcrossing rates because estimates are constrained to a maximum value of one. In the current analysis such biases probably did not affect the results as fruits were classified as either selfed or outcrossed.

\section{Environmental variation in outcrossing rates}

The large variance for family outcrossing rate estimates in I. fulva and I. hexagona indicates that environmental variation as well as statistical error must have contributed to the among flower differences observed (Morgan \& Barrett, 1990). Environmental effects on the proportion of selfed and outcrossed progeny produced would be expected in facultative outcrossing species, which do not strictly limit the success of self pollen (M. B. Cruzan \& S. C. H. Barrett, unpublished data). Although outcross pollen is typically favoured in these species, either through differences in the competitive ability of pollen (Bowman, 1987; Casper et al., 1988; Cruzan \& Barrett, 1993) or the preferential maturation of outcrossed ovules (Rigney et al., 1993), these mating systems are sensitive to the composition of pollen loads deposited on the stigmas of flowers ( $M$. B. Cruzan \& S. C. H. Barrett, unpublished data). The mixed mating system that results from incomplete limitation of self-pollen success would be sensitive to the level of pollinator activity and the abundance of flowers bearing self and outcross pollen. The response of outcrossing rates in $I$. fulva and $I$. hexagona to environmental variables indicates that these species may possess mechanisms that preferentially produce outcrossed progeny but also allow selfing.

With controlled pollinations plants having mixed mating systems can display linear responses to the size and composition of pollen loads (M. B. Cruzan \& S. C. $\mathrm{H}$. Barrett, unpublished data) but normal pollination conditions may produce discontinuous variation in the composition of progeny arrays among flowers. The limited amount of time that the stigmas of these Iris flowers are receptive, combined with potentially low 
levels of pollinator activity (M. B. Cruzan and M. L. Arnold, unpublished data), suggests that individual flowers may receive pollen from only a few visits. A low visitation rate would make the mating systems of flowers subject to the flight patterns of individual pollinators; the composition of the pollen load received by a flower may be primarily from only a few flowers (Thomson \& Thomson, 1989). The broad ranges of outcrossing rates in $I$. fulva and I. hexagona probably reflect an underlying discontinuous distribution of selfing and outcrossing probabilities that result from infrequent pollinator visits and the local abundance of flowers bearing self and outcross pollen.

The response of the frequency of outcrossing in $I$. hexagona to the number of pollen-bearing flowers on the same stem and on other individuals in the population may be a consequence of its high density and random distribution of genotypes. In I. fulva, on the other hand, the sparse distribution of the population combined with a high level of asexual reproduction and the response of pollinators to flowering density may have resulted in changes in outcrossing rates that were opposite to those predicted from donor flower densities. As the I. fulva population has apparently existed for a relatively long period of time, vegetative reproduction may have produced groups of genetically identical individuals that are separated by several metres. Anecdotal observations indicate that at least some of the I. fulva stems that were treated as separate individuals were derived from a single rhizome. Pollen transfers among plants in the same patch would be equivalent to selfing and would result in a decrease in outcrossing rate estimates.

The increase in the frequency of outcrossing with the number of flowers open on the same stem in I. fulva may be a consequence of pollinator behaviour. Given the relatively dispersed distribution of individuals in this population, plants bearing more flowers may be more attractive to pollinators and hence have a higher probability of receiving outcross pollen. Rarity of pollinators could result in decreases in outcrossing frequency when more flowers were open in a patch. With

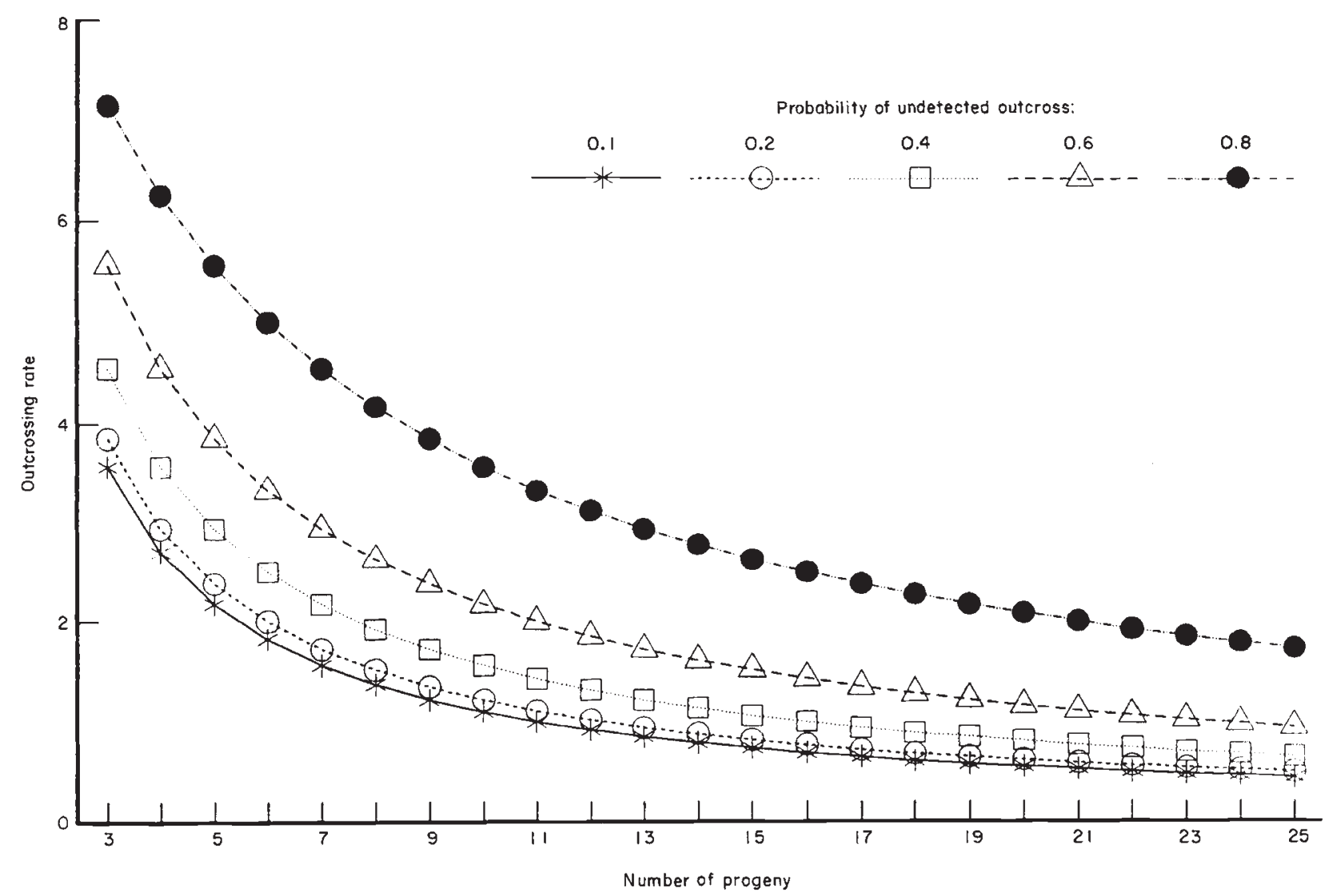

Fig. 2 Predicted minimum outcrossing rates for maternal genotypes differing in their predicted proportion of undetected outcross matings $P(u)$ with different progeny array sizes. 
low pollinator activity the number of visits per flower would be reduced when flower densities were high and plants would receive less outcross pollen. Although both pollen vector behaviour and interplant selfing could contribute to the observed responses of outcrossing frequency to flower density in I. fulva, the importance of each cannot be discerned without more detailed information on pollinator activity patterns and the clonal structure of the population.

The decrease in outcrossing frequency and seed set later in the flowering season in both Iris species may have been the result of a decrease in pollinator abundance or physiological differences among flowers on the same stem. Reduced ovule numbers in flowers opening later compared with the first flowers opening on a plant have been observed in other taxa (Thomson, 1989). Self-incompatibility systems have also been known to break down in later opening flowers (de Nettancourt, 1977), which would produce an increase in the selfing frequency of these flowers. Detailed analyses of the floral biology of these species may help reveal the mechanisms responsible for the among flower differences in outcrossing frequency.

The patterns of selfing and outcrossing observed in these sympatric Iris species may reveal some clues about the potential for hybrid seed formation. Observations indicate that the formation of seeds resulting from interspecific matings is rare in this system and tends to occur when interspecific flowers outnumber intraspecific flowers (Arnold et al., 1993). The low frequency of intraspecific outcross pollen donors appears to contribute to higher probabilities of selfing, and, if the prepotency of self pollen is more equivalent to interspecific pollen, may create an opportunity for hybrid seed formation.

Although it has been hypothesized that environmental variation could affect outcrossing rates at the level of the individual flower, few data have been collected to examine the effects of ecological factors on family outcrossing rates. Indeed, a certain amount of scepticism has been expressed over the ability of the available methods to provide precise enough estimates to be of much utility for this type of analysis (Morgan \& Barrett, 1990). Given the importance of the mating system for the evolution of plant species, establishing how components of floral biology affect the frequency of selfing and outcrossing stands as a major challenge for plant evolutionists (Brown, 1990). Utilizing analyses, such as in the present study, that give estimates of the mating system for individual fruits may provide important information on how ecological and physiological aspects of plant reproductive biology determine the frequency of outcrossing. This type of analysis may also help to identify characters that are important for the evolution of plant mating systems.

\section{Acknowledgements}

We thank S. Hodges, M. Morgan and K. Ritland for commments on the manuscript, B. McCaig for assistance with the data analysis and $\mathrm{K}$. Ritland for supplying copies of his mating system programs and advice on their use. We are grateful to L. Talbot for permission to work on his property. This work was supported by NSF grant BSR-9106666 (M.L.A. and J.L.H.), a University of Georgia Faculty Research Grant (M.L.A.) and a grant from the American Iris Society Foundation (M.L.A.).

\section{References}

ANDERSON, E. 1949. Introgressive Hybridization. John Wiley \& Sons, New York.

ARNOLD, M. L., BENNETT, B. D. AND ZIMMER, E. A. 1990a. Natural hybridization between Iris fulva and I. hexagona: pattern of ribosomal DNA variation. Evolution, 44, 1512-1521.

ARNOLD, M. L., BUCKNER, C. M. AND RoBINSON, J. J. 1991. Pollenmediated introgression and hybrid speciation in Louisiana irises. Proc. Natl. Acad. Sci., U.S.A., 88, 1398-1402.

ARNOLD, M. L., HAMRICK, J. L. AND BENNETT, B. D. 1990b. Allozyme variation in Louisiana irises: a test for introgression and hybrid speciation. Heredity, 65, 297-306.

ARNOLD, M. L., HAMRICK, J. L. AND BENNETT, B. D. 1993. Interspecific pollen competition and reproductive isolation in Iris. J. Heredity, 84, 13-16.

ARNOLD, M. L., ROBINSON, J. J., BUCKNER, C. M. AND BENNETT, B. D. 1992. Pollen dispersal and interspecific gene flow in Louisiana irises. Heredity, 68, 399-404.

BARRETT, S. C. H. AND ECKERT, C. G. 1990. Variation and evolution of mating systems in seed plants. In: Kawano, S. (ed), Biological Approaches and Evolutionary Trends in Plants, Academic Press, London, pp. 229-254.

BARRETT, S. C. H. AND HUSBAND, B. C. 1990. Variation in outcrossing rates in Eichhornia paniculata: the role of demographic and reproductive factors. Plant Species Biol., 5 , $41-55$

BoWman, R. N. 1987. Cryptic self-incompatibility and the breeding system of Clarkia unguiculata (Onagraceae). Am. J. Bot., 74, 471-476.

BROWN, A. H. D. 1990. Genetic characterization of plant mating systems. In: Brown, A. H. D., Clegg, M. T., Kahler, A. L. and Weir, B. S. (eds) Plant Population Genetics, Breeding and Genetic Resources, Sinauer Associates, Sunderland, Mass, pp. 145-162.

BROWN, A. H. D. AND ALlARD, R. W. 1970. Estimation of the mating system in open pollinated maize populations using allozyme polymorphisms. Genetics, 66, 133-145.

BROWN, A. H. D., BARRETT, S. C. H. AND MORAN, G. F. 1985, Mating system estimation in forest trees: models, methods and meanings. In: Gregorius, H. R. (ed), Population Genetics in Forestry, Springer-Verlag, Berlin, pp. 32-49. 
CASPER, B. B., SAYIGH, L. S. AND LEE, S. S. 1988. Demonstration of cryptic incompatibility in distylous Amsinckia douglasiana. Evolution, 42, 248-253.

CRUZAN, M. B. AND BARRETT, S. C. H. 1993. Contribution of cryptic incompatibility to the mating system of Eichhornia paniculata. Evolution, 47, 925-934.

ELLSTRAND, N. C. AND FOSTER, K. W. 1983. Impact of population structure on the apparent outcrossing rate of grain sorghum (Sorghum bicolor). Theor, and Appl. Genet., 66, 323-327.

ENNOS, R. A. AND CLEGG, M. T. 1982. Effect of population substructuring on estimates of outcrossing rate in plant populations. Heredity, 48, 283-292.

FAEGRI, K. AND VAN DER PIJL, L. 1966. The Principles of Pollination Ecology. Pergamon Press, New York.

HARDING, J. 1970. Genetics of Lupinus. II. The selective disadvantage of the pink flower color mutant in Lupinus nanus, Evolution, 24, 120-127.

HARDING, J., MANKINEN, C. B. AND ELLIOT, M. 1974. Genetics of Lupinus. VII. Outcrossing, autofertility and variability in natural populations of the Nanus group. Taxon, 23, 729-738.

HARDING, J. AND TUCKER, C. L. 1964. Quantitative studies on mating systems. I. Evidence for the non-randomness of outcrossing in Phaseolus lunatus. Heredity, 19, 369-381.

HOLSINGER, K. E. 1991. Mass-action models of plant mating systems: the evolutionary stability of mixed mating systems. Am. Nat, 138, 606-622.

HUMPREYS, M. O. AND GALE, J. S. 1974. Variation in wild populations of Papaver dubium. VIII. The mating system. Heredity, 33, 33-41.

LANDE, R. AND SCHEMSKE, D. W. 1985. The evolution of selffertilization and inbreeding depression in plants. I. Genetic models. Evolution, 39, 24-40.

MORGAN, M. T. AND BARRETT, S. C. H. 1990. Outcrossing rates and correlated mating within a population of Eichhornia paniculata (Pontederiaceae). Heredity, 64, 271-280.

MOTTEN, A. F. AND ANTONOVICS, J. 1992. Determinants of outcrossing rate in a predominantly self-fertilizing weed, Datura stramonium (Solanaceae). Am. J. Bot., 79 , 419-427.

NETTANCOURT, D. DE. 1977. Incompatibility in Angiosperms. Springer-Verlag, Berlin.

RANDOLPH, L. F., NELSON, 1. S. AND PLAISTED, R. L. 1967. Negative evidence of introgression affecting the stability of
Louisiana Iris species. Cornell Univ. Ag. Exper. Stat. Mem., 398, 1-56.

RIGNEY, L. P., THOMSON, J. D., CRUZAN, M. B. AND BRUNET, J. 1993. Differential success of pollen donors in a self-compatible lily. Evolution, 47, 915-924.

RILEY, H. P. 1938. A character analysis of colonies of Iris fulva, Iris hexagona var. giganticaerulea and natural hybrids. Am. J. Bot., 25, 727-738.

RITLAND, K. 1984. The effective proportion of self-fertilization with consanguineous matings in inbred populations. Genetics, 106, 139-152.

RITLAND, K. 1986. Joint maximum likelihood estimation of genetic and mating structure using open-pollinated progenies. Biometrics, 42, 25-43.

RITLAND, K. AND GANDERS, F. R. 1985. Variation in the mating system of Bidens menziesii (Asteraceae) in relation to population substructure. Heredity, 55, 235-244.

RITLAND, K. AND JAIN, S. K. 1981. A model for the estimation of outcrossing rate and gene frequencies using $n$ independent loci. Heredity, 47, 35-52.

SAS INSTITUTE. 1985. SAS User's Guide: Statistics, version 5. SAS Institute, Cary, NC.

SCHEMSKE, D. W. AND LANDE, R. L. 1985. The evolution of selffertilization and inbreeding depression in plants. II. Empirical observations. Evolution, 39, 41-52.

SCHOEN, D. J. 1982. The breeding system of Gilia achilleifolia: variation in floral characteristics and outcrossing rate. Evolution, 36, 352-360.

SCHOEN, D. J. AND CLEGG, M. T. 1984. Estimation of mating system parameters when outcrossing events are correlated. Proc. Natl. Acad. Sci. U.S.A., 81, 5258-5262.

SHAW, D. V., KAHLER, A. L. AND ALLARD, R. W. 1981. A multilocus estimator of mating system parameters in plant populations. Proc. Natl. Acad. Sci. U.S.A., 78, 1298-1302.

SMYTH, C. A. AND HAMRICK, J. L. 1987. Realized gene flow via pollen in artificial population of musk thistle, Carduus nutans. Evolution, 41, 613-619.

THOMSON, J. D. 1989. Deployment of ovules and pollen among flowers within inflorescences. Evol. Trends Plants, 3, 65-68.

THOMSON, J. D. AND THOMSON, B. A. 1989. Dispersal of Erythronium grandiflorum pollen by bumblebees: implications for gene flow and reproductive success. Evolution, 43, 657-661. 